\title{
Empirical estimation of uncertainties of Charpy impact testing transition temperatures for an RPV steel
}

\author{
Bernard Marini* \\ Université Paris-Saclay, CEA, Service de Recherches Métallurgiques Appliquées, 91191 Gif-sur-Yvette, France
}

Received: 28 April 2020 / Received in final form: 21 August 2020 / Accepted: 16 October 2020

\begin{abstract}
The aim of the present work is to derive empirically a simple expression of the uncertainties on Charpy transition temperatures $(T T)$, which depends only on the test temperatures and the number of tests at each of these temperatures. Calculations of the TT uncertainties of a RPV steel are performed based on an empirical representation of Charpy test results and a Monte Carlo procedure to generate large numbers of data sets for different test matrices. Applying usual procedures to determine the $T T$ to the generated data sets gives access to the distributions of these quantities from which the uncertainties are calculated.An analytical expression for these uncertainties is proposed.
\end{abstract}

\section{Introduction}

Because of its simplicity and robustness, Charpy impact testing is widely used to evaluate the toughness of structural steels from acceptance tests to ageing monitoring. Minimum values of fracture energy at reference temperatures is used for acceptance tests but in-serviceageing monitoring requires determination of temperatures corresponding to conventional levels of fracture energy. For nuclear application of ferritic steels, the conventional levels are $28 \mathrm{~J}, 41 \mathrm{~J}$ and $68 \mathrm{~J}$; the $56 \mathrm{~J}$ level is also used in France specifically in case of neutron irradiation [1]. These levels of energy are in the transition temperature domain where the fracture energy increases rapidly with temperature. The corresponding temperatures are called "transition" temperatures $(T T)$. In addition, the fracture energy in the temperature domain corresponding to the ductile behaviour of the steel is also used and called the upper shelf energy (USE). Ageing of steels during operation could possibly modifythe transition temperatures, as well as the upper shelf energy. These shifts are measures of the embrittlement of the material and must be carefully determined to assess the ability of a component to fulfil its function in operating or accidental conditions. Therefore, the knowledge of the uncertainties in the determination of the transition temperatures and upper shelf energy is of the utmost importance for safe operations.

Uncertainties and confidence intervals on the transition temperatures could be estimatedfrom the statistics of the

\footnotetext{
* e-mail: Bernard.Marini@cea.fr
}

parameters of the fit function and are dependant of the dataset [2-5]. This means that, in this case, the uncertainties are not related only to the methodology of measure but also to the result of the measure itself. The aim of the present work is to derive a simple expression of the uncertainties on transition temperatures, which depends only on the test matrix defined by the test temperatures and the number of tests for each of these temperatures. In order to define this expression, estimations of the $T T$ uncertainties of a representative 16MND5 type RPV steel are performed considering different test matrices. These evaluations are based on an empirical representation of Charpy test results and a Monte Carlo procedure to generate large numbers of data sets for different test matrices. Applying usual procedures to determine the TT to the generated data sets gives access to the distributions of these quantities from which the uncertainties are calculated.

\section{Material and data base}

The material is taken at $3 / 4$ thickness of a nozzle cut-off of a shell supporting the pipes of the primary circuit. The location of the sampling is outside of the macro-segregated zone and reduces the risk to intercept ghost lines in Charpy specimens. Therefore, the present evaluation of uncertainty does not consider macro-segregation or ghost lines induced scatter but lower scales heterogeneities (microsegregations, manganese sulphides,...) are taken into account through the use of the representative Charpy data. Uncertainties relative to specimen preparation and test machine are also included in this analysis. 
Table 1. Chemical composition of the material.

\begin{tabular}{llllllll}
\hline $\mathrm{C}$ & $\mathrm{Mn}$ & $\mathrm{Ni}$ & $\mathrm{Mo}$ & $\mathrm{Si}$ & $\mathrm{Cr}$ & $\mathrm{Al}$ & $\mathrm{N}$ \\
\hline 0.159 & 1.37 & 0.70 & 0.50 & 0.24 & 0.17 & 0.024 & 0.007 \\
\hline $\mathrm{S}$ & $\mathrm{P}$ & $\mathrm{Cu}$ & $\mathrm{Sn}$ & $\mathrm{As}$ & $\mathrm{Co}$ & $\mathrm{V}$ & $\mathrm{O}(\mathrm{ppm})$ \\
\hline 0.008 & 0.005 & $<0.01$ & 50 & 160 & $<0.01$ & $<0.01$ & 35 \\
\hline
\end{tabular}

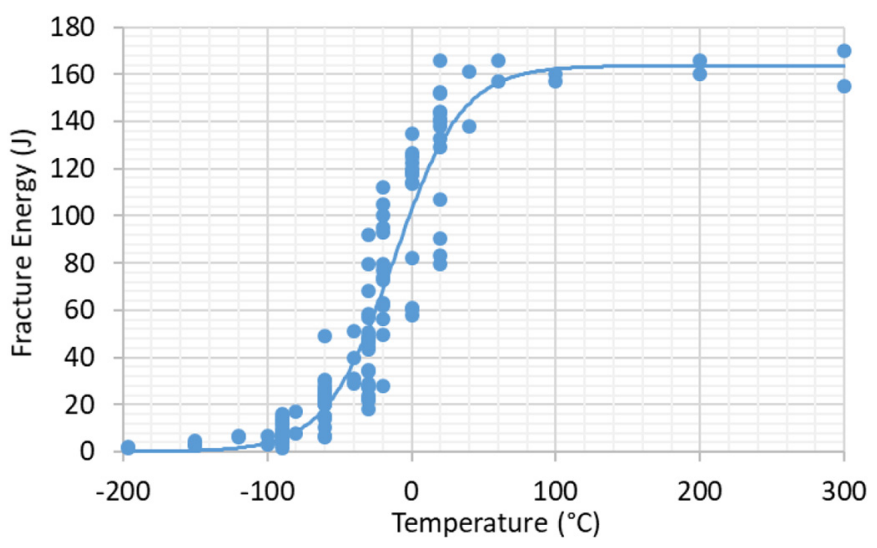

Fig. 1. Charpy test results and transition curve.

The material fabrication processes as well as its chemical composition (Tab.1) satisfy the RCC-M specificationsfor 16MND5 heavy forgings [6]. The heat treatments of the shell after forging are performed to avoid the formation of hydrogen flakes, to homogenize the material and refine the grain size. The last quench is followed by a tempering and a stress relief heat treatment. The microstructure is a granular bainite with few percent of proeutectoid ferrite.

Metallurgical and mechanical characterizations of the material have been mainly obtained during three $\mathrm{PhD}$ thesis [7-9] but were later completed for this study. Charpy specimens were machined in LS orientation. 142 tests results are available in the temperature range $[-196$, $+300^{\circ} \mathrm{C}$ (Fig. 1). The transition curve of the fracture energy $K V$ is described by a hyperbolic tangent function parametrized by the least squared method:

$$
K_{V}=\frac{U S E}{2}\left(1+\tan h\left(\frac{T-T_{t}}{T_{h w}}\right)\right)
$$

where USE is the upper shelf energy, $T_{t}$ is the transition temperature at $0.5 U S E$ and $T_{h w}$ is the half width of the transition domain.

Table 2 presents the conventional transition temperatures and upper shelf values. We define the transition temperature range as the temperature interval between T28 and T68, i.e. approximatively $\left[-50,-20^{\circ} \mathrm{C}\right]$. This interval will be used to evaluate the position of the test matrices on the temperature axis.

\section{Numerical simulation of the uncertainty}

The simulation of the uncertainties of a given test matrix is based on a Monte Carlo method applied to an analytical representation of the data base.
Table 2. Conventional transition temperatures and upper shelf.

\begin{tabular}{|c|c|c|c|c|}
\hline $\begin{array}{l}\text { T28 } \\
\left({ }^{\circ} \mathrm{C}\right)\end{array}$ & $\begin{array}{l}\text { T41 } \\
\left({ }^{\circ} \mathrm{C}\right)\end{array}$ & $\begin{array}{l}T 56 \\
\left({ }^{\circ} \mathrm{C}\right)\end{array}$ & $\begin{array}{l}\text { T68 } \\
\left({ }^{\circ} \mathrm{C}\right)\end{array}$ & $\begin{array}{l}\text { Upper } \\
\text { Shelf }(\mathrm{J})\end{array}$ \\
\hline-49.06 & -37.77 & -27.42 & -20.10 & 163.58 \\
\hline
\end{tabular}

\subsection{Representation of the data}

Because of the unbalanced number of results for the different test temperatures, an analytic description of the database is used instead of the individual values. The Charpy fracture energies are usually assumed to obey a Weibull distribution in the lower part of the transition region [10-13]. However, it is known that the standard deviation of the fracture energy goes through a maximum, approximatively at $T_{t}$, associated with the possible development of a bimodality. Therefore, we choose here to use bimodal distributions to represent the variation of the data independently at each test temperature. These distributions result from the mixing of two Weibull distributions:

$$
\begin{aligned}
P_{f}\left(E \leq E_{f}, T\right)= & \gamma\left[1-\exp \left(\left(\frac{E_{f}}{E_{l}}\right)^{m_{l}}\right)\right] \\
& +(1-\gamma)\left[1-\exp \left(\left(\frac{E_{f}}{E_{h}}\right)^{m_{h}}\right)\right] .
\end{aligned}
$$

At the test temperature $T, \gamma$ is the fraction of the specimens failing with a "low" energy, $E_{l}, m_{l}$ are the parameters of the distribution of the fracture energy $E_{f}$ for the specimens failing with low energy and $E_{h}, m_{h}$ are the parameters for the specimens failing with higher energy. Low and high are relative to the meanvalue of the fracture energy at the considered test temperature. The values of the parameters $\gamma, E_{l}, m_{l}, E_{h}, m_{h}$ are adjusted independently for each temperature (Fig. 2a). Linear interpolations between experimental temperatures are performed if needed for the test matrix (Fig. 2b). The distribution of fracture energy on the lower shelf region $\left[-196,-100^{\circ} \mathrm{C}\right]$ is assumed to be temperature independent and all data are considered to belong to the same distribution. The same assumption is made for data on the upper shelf $[+60$, $+300{ }^{\circ} \mathrm{C}$.

In the transition region, the mixing law gives a satisfactory description of the data. It could be noted that the ductile crack propagation before cleavage fracture which appears typically above $50 \mathrm{~J}$ for this RPV steel, could give a clue to explain the shape of the fracture energy 


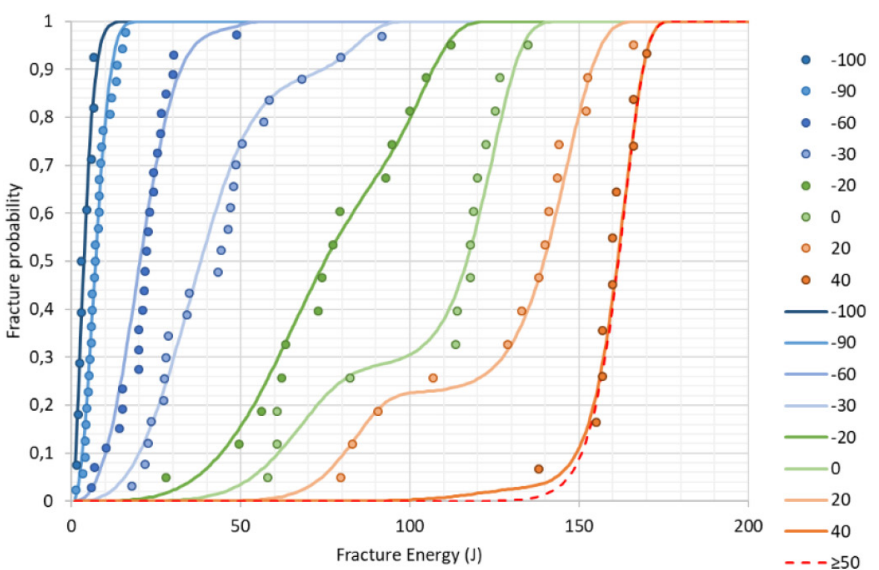

(a)

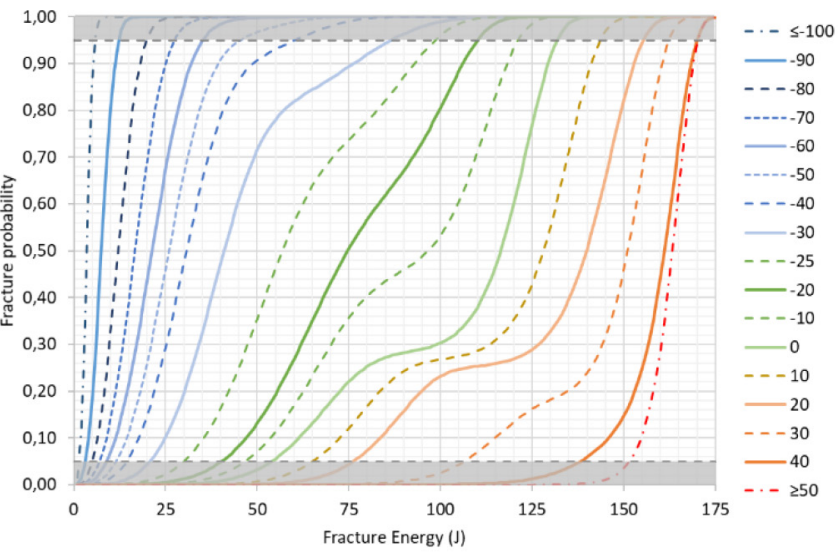

(b)

Fig. 2. Data base from lower shelf $\left(\mathrm{T}<-100^{\circ} \mathrm{C}\right)$ to upper shelf $\left(\mathrm{T}>50^{\circ} \mathrm{C}\right)$. (a) Fittings of equation (1) at different temperatures. (b) Data distributions for the modelling of uncertainties. The parts of these distributions below $5 \%$ and above $95 \%$ (grey zones) are not used in the modelling of uncertainties.

distributions. However, there is no simple correlation between equation (2) and the fracture initiation and propagation modes. Consequently, in the present work, no physical meaning is claimed for equation (2) which allows a simple and flexible description of the data base.

\subsection{Simulation procedure}

The numerical procedure aim is to simulate a large number of determinations of the $T T$ allowing the study of their distributions for a given test matrix. It is based on a simple random sampling with replacement applied of the distributions defined by equation (2). The evaluation of the quantities needed to evaluate the uncertainties on transition temperatures associated to a chosen test matrix is obtained through the following procedure:

- Step 1: Monte Carlo method is used to obtain a set of data from equation (2) according to the test matrix under evaluation. To avoid unrealistic values, only data corresponding to a probability in the interval $[0,05$, $0,95]$ are retained.

- Step 2: The transition temperatures T28, T41, T56 and T68 are determined froma hyperbolic tangent function (Eq. (1)) parametrized by least squares method on the data set obtained in step 1.

- Steps 1 and 2 are repeated 10000 times thanks to an Octave script [14].

- Then the transition temperatures are statistically characterized through their mean, standard deviation and other statistical characteristics of their distributions.

Two quantities are considered to derive the uncertainty: the precision and the accuracy. The precision $\sigma$ is quantified by the standard deviation of the mean value of T28, T41, T56, T68 and USE of the sampled data set. The accuracy (or error) $\varepsilon$ is the difference between the true values and computed values of transition temperaturesmeans; i.e., the mean value of T28, T41, T56, T68 and USE derived from resampled data points, which follows equation (2). Therefore, the uncertainty $u$ of a transition temperature $T_{k}$ is the sum in quadrature of these two quantities:

$$
u\left(T_{k}\right)=\sqrt{\sigma^{2}+\varepsilon^{2}} .
$$

\subsection{Assessment of the simulation}

The test matrix of the database is used to assess the simulation procedure. For this assessment, the "true" values of transition temperatures and upper shelf used to compute the accuracy $e$ are here the values obtained from the fitting of the database (Tab. 2).

Table 3 and Figure 3 present the results of the 10,000 computations of transition temperatures and upper shelf with the test matrix of the database. The mode of sampled transition temperatures is close to these obtained by overall data base: for the transition temperatures, the accuracy values are smaller than the standard deviation. The main part of uncertainty on transition temperatures comes from the precision which is primally in relation with the data scatter in the transition domain. We assume that the accuracy values are small enough compared to usual experimental errors to conclude that the simulation procedure is satisfactory.

\subsection{Definition of the reference case}

The determination of the accuracy needs the definition of a reference case with "true" values of transition temperatures and upper shelf. The database values cannot be considered as true because of the size of the population and the imperfections in its modelling. So, we have defined "true" values as the results of the simulation with a test matrix with a large number of specimens (600) distributed on 7 test temperatures between -90 and $+100{ }^{\circ} \mathrm{C}$ (Tab. 4$)$. We 
Table 3. Mean, precision and accuracy obtained from 10000 data sets with the test matrix of the database.

\begin{tabular}{llllll}
\hline & $\begin{array}{l}\text { T28 } \\
\left({ }^{\circ} \mathrm{C}\right)\end{array}$ & $\begin{array}{l}\text { T41 } \\
\left({ }^{\circ} \mathrm{C}\right)\end{array}$ & $\begin{array}{l}\text { T56 } \\
\left({ }^{\circ} \mathrm{C}\right)\end{array}$ & $\begin{array}{l}\text { T68 } \\
\left({ }^{\circ} \mathrm{C}\right)\end{array}$ & $\begin{array}{c}\text { Upper Shelf } \\
(\mathrm{J})\end{array}$ \\
\hline Mean & -48.26 & -37.31 & -27.28 & -20.21 & 165.70 \\
\hline Precision $(\sigma)$ & 1.75 & 1.38 & 1.28 & 1.37 & 2.26 \\
Accuracy / DB $(\varepsilon)$ & -0.80 & -0.46 & -0.14 & 0.11 & 2.12 \\
Uncertainty & 1.92 & 1.45 & 1.29 & 1.37 & 3.10 \\
\hline
\end{tabular}
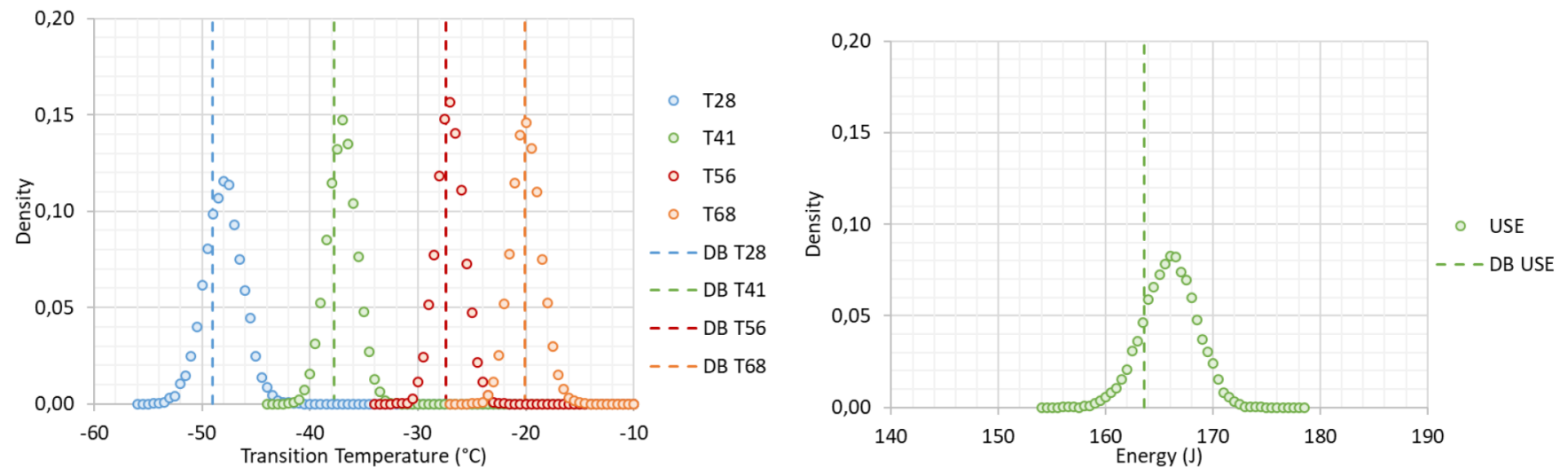

Fig. 3. Comparison of the computed distributions (circles) with thedata base values (dotted lines). Class size is $0.5{ }^{\circ} \mathrm{C}$ for $\mathrm{TT}$ and $0.5 \mathrm{~J}$ for USE.

Table 4. Test matrix of the Reference Case (RC).

\begin{tabular}{lllllllll}
\hline Test Temperature $\left({ }^{\circ} \mathrm{C}\right)$ & $\mathrm{N}$ & -90 & -60 & -30 & -20 & 0 & 20 & 100 \\
\hline Number of specimens & 600 & 50 & 100 & 100 & 100 & 100 & 100 & 50 \\
\hline
\end{tabular}

Table 5. Mean, precision, skewness and Kurtosis coefficient of the distributions for the Reference Case.

\begin{tabular}{llllll}
\hline & T28 $\left({ }^{\circ} \mathrm{C}\right)$ & T41 $\left({ }^{\circ} \mathrm{C}\right)$ & T56 $\left({ }^{\circ} \mathrm{C}\right)$ & T68 $\left({ }^{\circ} \mathrm{C}\right)$ & Upper Shelf $(\mathrm{J})$ \\
\hline Mean & -49.22 & -38.23 & -28.13 & -20.99 & 162.80 \\
Precision $(\sigma)$ & 0.96 & 0.72 & 0.59 & 0.58 & 1.07 \\
\hline & T28 & T41 & T56 & T68 & Upper Shelf \\
\hline Skewness & -0.01 & 0.01 & 0.01 & 0.01 & -0.10 \\
Excess Kurtosis & 0.01 & -0.01 & 0.00 & 0.00 & 0.12 \\
\hline
\end{tabular}

assume that the values resulting of the simulations with this test matrix (Tab. 5) are the true values from which the accuracy of the other test matrices is evaluated. As the reference case represents the "truth", its accuracy is equal to 0 and its uncertainty is equal to its precision. It is interesting to note that the skewness and Kurtosis coefficient indicate that the transition temperatures and, to a less extent, the upper shelves distributions are nearly symmetric and mesokurtic. As shown in Figure 4, these distributions can befairly described with normal distributions of the computed means and standard deviations.

\subsection{Repeatability of uncertainty evaluation}

Because of the high variability of the fracture energy in the transition regime, test matrices with a realistic number of specimens (typically 12-30) will lead to significant fluctuations of the transition temperatures. Even with 10,000 sets of data, some variation of the mean values and other characteristics could be expected. We have checked these variations on a test matrix built in agreement with the codification (MC1222 "Tracé de la courbe de transition" from [6]). The test matrix is composed of 18 tests: 3 on 

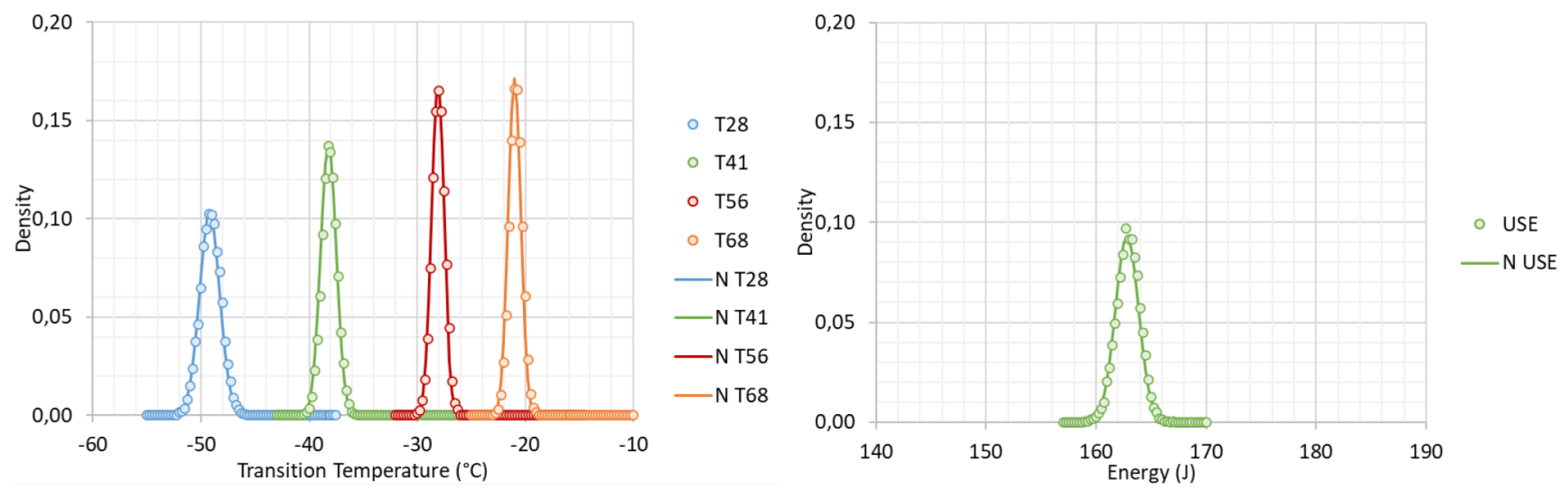

Fig. 4. Comparison of the computed distributions (circles) with the normal distributions of the same mean and standard deviation (solid lines). Class size of the computed distributions is $0.25^{\circ} \mathrm{C}$ or $0.25 \mathrm{~J}$.

Table 6. The "RCC-M" test matrix.

\begin{tabular}{llllllll}
\hline Test Temperature $\left({ }^{\circ} \mathrm{C}\right)$ & $\mathrm{N}$ & -60 & -40 & -20 & 0 & 20 & 100 \\
\hline Number of specimens & 18 & 3 & 3 & 3 & 3 & 3 & 3 \\
\hline
\end{tabular}

Table 7. Mean, precision, skewness and Kurtosis coefficient of the distributions for the "RCC-M" test matrix.

\begin{tabular}{llllll}
\hline & T28 $\left({ }^{\circ} \mathrm{C}\right)$ & T41 $\left({ }^{\circ} \mathrm{C}\right)$ & T56 $\left({ }^{\circ} \mathrm{C}\right)$ & T68 $\left({ }^{\circ} \mathrm{C}\right)$ & Upper Shelf $(\mathrm{J})$ \\
\hline Mean & -49.13 & -38.24 & -28.25 & -21.18 & 163.00 \\
Precision $(\sigma)$ & 4.68 & 3.52 & 3.20 & 3.51 & 4.44 \\
Accuracy $(\varepsilon)$ & -0.34 & -0.13 & 0.06 & 0.19 & 0.48 \\
Uncertainty & 4.68 & 3.52 & 3.21 & 3.53 & 4.47 \\
\hline & T28 & $T 41$ & $T 56$ & T68 & Upper Shelf \\
\hline Skewness & -0.36 & -0.04 & 0.19 & 0.34 & -0.19 \\
Excess Kurtosis & 0.51 & 0.11 & -0.03 & 0.16 & 0.79 \\
\hline
\end{tabular}

the upper shelf $\left(+100^{\circ} \mathrm{C}\right)$ and 15 in the transition region (Tab. 6).

The results of a first run with the "RCC-M" test matrix are presented in Table 7 and Figure 5. Compared to the reference case (RC), the precision is loweras expected. However, the accuracy of the test matrix is s satisfactory when compared, on one hand, to measurement uncertainties and, on the other hand, to application needs. Consequently, the uncertainties are mainly due to the lack of precision related to the number of specimens. One can note that the used test matrix leads to a low uncertainty for T56 and a higher for T28, T41 and T68 have almost the same intermediate uncertainties. The skewness and Kurtosis coefficients of T28 and USE distributions indicate a derivation from symmetry and mesokurticity which can be seen by comparing these distributions with the normal ones (Fig. 5).

Ten runs of the modelling procedure were successively performed for this test matrix. The different values of the transition temperatures and upper shelf as well as the associated uncertainties are shown in Figure 6. The results are remarkably reproductible and the maximum difference between uncertainties varies from 0.08 to $0.05^{\circ} \mathrm{C}$ for the transition temperatures and is equal to $0.16 \mathrm{~J}$ for the USE. Assuming a Student distribution of the means, the confidence interval at $99.9 \%$ is $0.05^{\circ} \mathrm{C}$ for $T T$ and $0.08 \mathrm{~J}$ for USE. So,in the context of these simulations, we consider that differences of uncertainties are significant, if they are equal or greater than $0.1^{\circ} \mathrm{C}$ for transition temperatures and $0.2 \mathrm{~J}$ for $U S E$.

\section{Results}

\subsection{Effect of the position of the test matrix on the transition temperatures uncertainties}

The number of specimens can be limited due to the available material quantities or the room in thermal or irradiation ageing devices. In these cases, the position of the test matrix with respect to the transition region could be of 

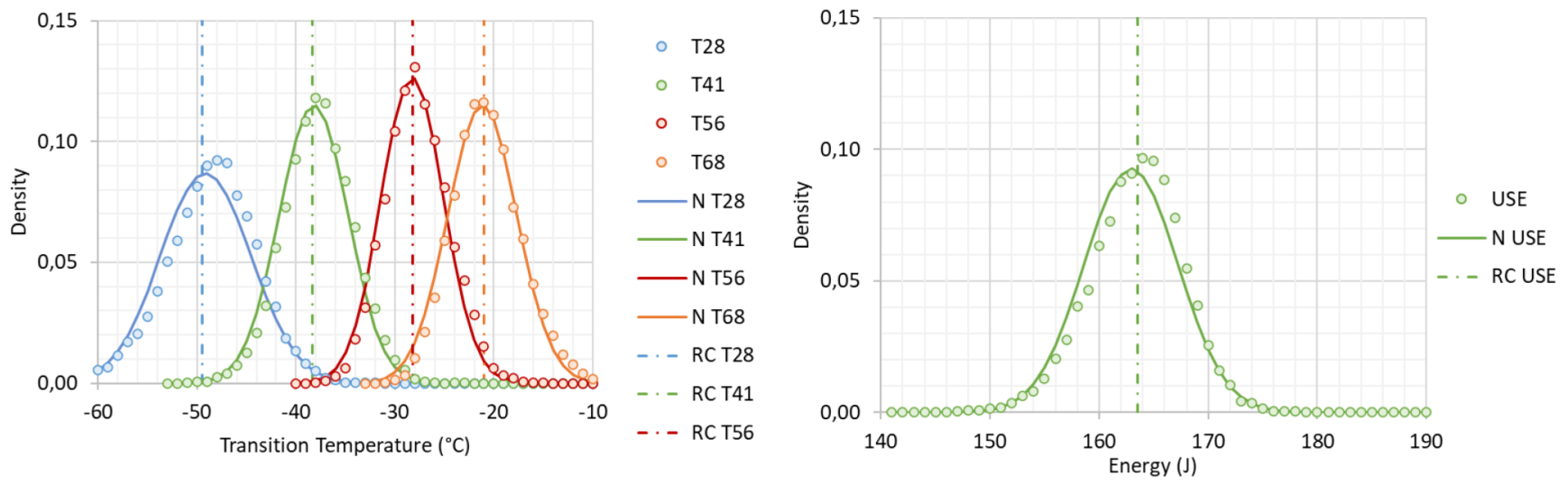

Fig. 5. Comparison of the computed distributions (circles) with the normal distributions of the same mean and standard deviation (solid lines) and the reference case values (vertical dotted lines). Class size is $1^{\circ} \mathrm{C}$ or $1 \mathrm{~J}$.
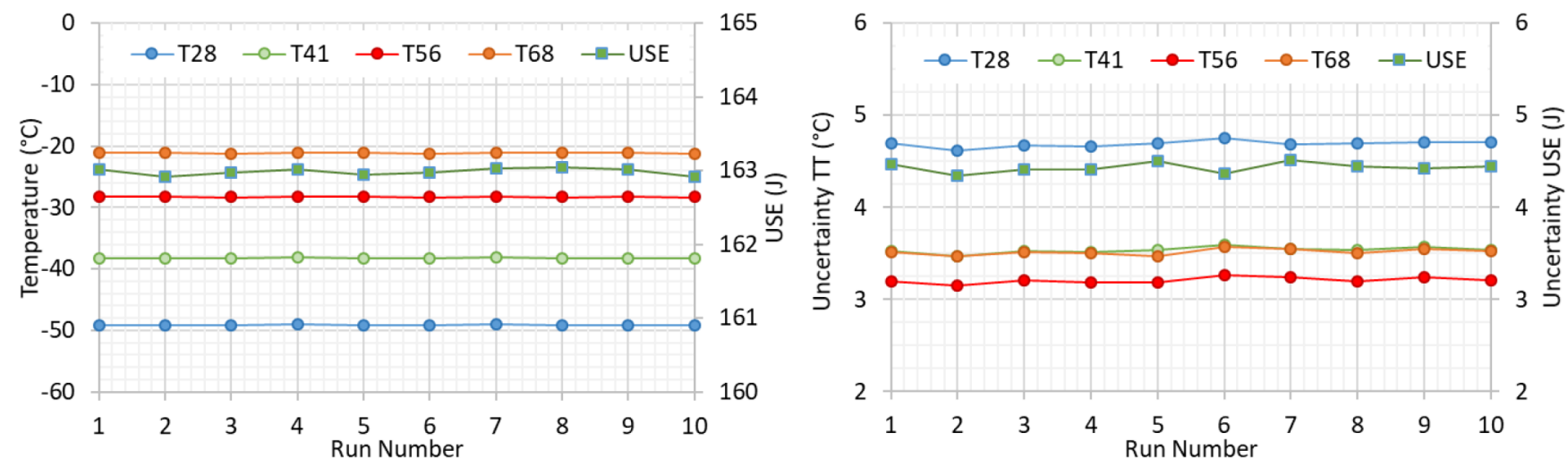

Fig. 6. Transition temperatures and associated uncertainties for the 10 runs using the RCC-M test matrix.

importance. In the following, we consider that we have 15, 20 or 25 specimens to determine as well as possible (i.e. with the lowest uncertainty) the transition temperatures. We choose to put 3 specimens to define the upper shelf and the remaining specimens in or around the transition temperaturesdomain. The step of test temperatures is $20^{\circ} \mathrm{C}$. The chosen test matrices are named AN-k, where $N \in\{15,20,25\}$ isthe total number of specimens and $k$ is the case number $\in\{1$ to 11$\}$ (Tab. 8).

In order to rationalize the results, we introduce the "shift of the test matrix" $S$ with respect to the transition temperatures region:

$$
S=\frac{1}{N} \sum_{i=1}^{n T} w_{i} \cdot n_{i}
$$

where $N$ is the number of specimens, $n T$ is the number of test temperatures, $w_{i}$ is the weight associated with the test temperature $i$ and $n_{i}$ is the number of tests performed at this temperature.

The weight of the tests in the transition temperatures domain defined by the interval [T28, T68] is equal to zero. Negative or positive weights are attributed to test temperatures, respectively, below or above the transition temperatures domain. Test temperature of $-20^{\circ} \mathrm{C}$ is considered to be for half in the transition temperature range, then the weight of this temperature is +0.5 . With these assumptions, the shifts of the test matrices A range from -0.23 up to 1.33 (Tab. 8).

The results of the uncertainty evaluation procedure applied to these test matrices are presented in Figure 7.

The dependences of uncertainties on $T T$ on the shift are described by parabolic functions (Figs. 7a-7d). The minimum of uncertainties on the different $T T$ is not reached for the same shift value; the higher the reference energy is, the higher is the optimum shift. The uncertainty evolutions for 15 and 20 specimens are tangent close to the minima of uncertainty; 25 specimens are needed to clearly reduce these minima and improve the uncertainty on the entire shift domain.

\subsection{Effect of the number of specimens on the transition temperatures uncertainties}

The uncertainty dependence on the number of specimens was studied on two sets of test matrices. The matrices of the first set are named " $B \imath$ " where " $i$ " is the number of specimens per test temperature varying from 2 to 20 
Table 8. Test matrices with 15,20 and 25 specimens. $N$ is the total number of tests and $n T$ is the number of test temperatures.

\begin{tabular}{|c|c|c|c|c|c|c|c|c|c|c|c|c|c|}
\hline \multicolumn{4}{|c|}{ Test temperature $\left({ }^{\circ} \mathrm{C}\right)$} & \multirow{2}{*}{$\frac{-100}{-2}$} & \multirow{2}{*}{$\frac{-80}{-1.5}$} & \multirow{2}{*}{$\frac{-60}{-1}$} & \multirow{2}{*}{$\frac{-40}{0}$} & \multirow{2}{*}{$\frac{-20}{+0.5}$} & \multirow{2}{*}{$\frac{0}{+1}$} & \multirow{2}{*}{$\frac{20}{+1.5}$} & \multirow{2}{*}{$\frac{40}{+2}$} & \multirow{2}{*}{$\frac{60}{+2}$} & \multirow{2}{*}{$\frac{100}{+2}$} \\
\hline & $\mathrm{We}$ & & & & & & & & & & & & \\
\hline Matrix & $\mathrm{N}$ & $\mathrm{nT}$ & Shift & & & & & & & & & & \\
\hline A15-1 & 15 & 5 & 0.00 & & 3 & 3 & 3 & 3 & & & & & 3 \\
\hline $\mathrm{A} 15-2$ & 15 & 5 & 0.50 & & & 3 & 3 & 3 & 3 & & & & 3 \\
\hline A15-3 & 15 & 5 & 1.00 & & & & 3 & 3 & 3 & 3 & & & 3 \\
\hline A15-4 & 15 & 6 & -0.23 & 2 & 3 & 2 & 3 & 2 & & & & & 3 \\
\hline A15-5 & 15 & 6 & 0.23 & & 2 & 3 & 2 & 3 & 2 & & & & 3 \\
\hline A15-6 & 15 & 6 & 0.73 & & & 2 & 3 & 2 & 3 & 2 & & & 3 \\
\hline $\mathrm{A} 15-7$ & 15 & 6 & 1.20 & & & & 2 & 3 & 2 & 3 & 2 & & 3 \\
\hline A15-8 & 15 & 7 & 0.00 & 2 & 2 & 2 & 2 & 2 & 2 & & & & 3 \\
\hline A15-9 & 15 & 7 & 0.47 & & 2 & 2 & 2 & 2 & 2 & 2 & & & 3 \\
\hline A15-10 & 15 & 7 & 0.93 & & & 2 & 2 & 2 & 2 & 2 & 2 & & 3 \\
\hline A15-11 & 15 & 7 & 1.33 & & & & 2 & 2 & 2 & 2 & 2 & 2 & 3 \\
\hline A20-1 & 20 & 7 & -0.05 & 2 & 3 & 3 & 3 & 3 & 3 & & & & 3 \\
\hline A20-2 & 20 & 7 & 0.45 & & 2 & 3 & 3 & 3 & 3 & 3 & & & 3 \\
\hline A20-3 & 20 & 7 & 0.95 & & & 2 & 3 & 3 & 3 & 3 & 3 & & 3 \\
\hline A20-4 & 20 & 8 & 0.03 & 2 & 3 & 3 & 3 & 2 & 2 & 2 & & & 3 \\
\hline A20-5 & 20 & 8 & 0.53 & & 2 & 3 & 3 & 3 & 2 & 2 & 2 & & 3 \\
\hline A20-6 & 20 & 8 & 0.98 & & & 2 & 3 & 3 & 3 & 2 & 2 & 2 & 3 \\
\hline A20-7 & 20 & 8 & 1.05 & & & 2 & 2 & 3 & 3 & 3 & 3 & 1 & 3 \\
\hline A20-8 & 20 & 9 & 0.35 & 2 & 2 & 2 & 3 & 2 & 2 & 2 & 2 & & 3 \\
\hline A20-9 & 20 & 9 & 0.78 & & 2 & 2 & 2 & 3 & 2 & 2 & 2 & 2 & 3 \\
\hline A20-10 & 20 & 10 & 0.45 & 2 & 2 & 2 & 2 & 2 & 2 & 2 & 2 & 1 & 3 \\
\hline A20-11 & 20 & 10 & 0.55 & 1 & 2 & 2 & 3 & 2 & 2 & 2 & 2 & 1 & 3 \\
\hline A 25-1 & 25 & 7 & -0.08 & 2 & 4 & 4 & 4 & 4 & 4 & & & & 3 \\
\hline A25-2 & 25 & 7 & 0.44 & & 2 & 4 & 4 & 4 & 4 & 4 & & & 3 \\
\hline A25-3 & 25 & 7 & 0.96 & & & 2 & 4 & 4 & 4 & 4 & 4 & & 3 \\
\hline A25-4 & 25 & 8 & -0.02 & 2 & 4 & 4 & 4 & 3 & 3 & 2 & & & 3 \\
\hline A $25-5$ & 25 & 8 & 0.50 & & 2 & 4 & 4 & 4 & 3 & 3 & 2 & & 3 \\
\hline A $25-6$ & 25 & 8 & 0.98 & & & 2 & 4 & 4 & 4 & 3 & 3 & 2 & 3 \\
\hline A $25-7$ & 25 & 8 & 1.12 & & & 2 & 2 & 4 & 4 & 4 & 4 & 2 & 3 \\
\hline A $25-8$ & 25 & 9 & 0.36 & 2 & 2 & 3 & 4 & 3 & 3 & 3 & 2 & & 3 \\
\hline A25-9 & 25 & 9 & 0.82 & & 2 & 2 & 3 & 4 & 3 & 3 & 3 & 2 & 3 \\
\hline A25-10 & 25 & 10 & 0.32 & 2 & 3 & 3 & 3 & 3 & 3 & 2 & 2 & 1 & 3 \\
\hline A25-11 & 25 & 10 & 0.60 & 1 & 2 & 3 & 3 & 3 & 3 & 3 & 3 & 1 & 3 \\
\hline
\end{tabular}

(Tab. 9). The number of test temperatures is 5 and the total number of specimens is 5.i. Of course, using a large number of specimens on the upper shelf is somewhat unrealistic but permits to maintain a constant test matrix shift when increasing the specimen number. One can note that the test matrix B3 is identical to matrix A5-2.

The results of the calculation using $\mathrm{Bi}$ matrices are presented in Figure 8. Uncertainty and precision are decreasing rapidly with the number of specimens in the transition temperature region. T41 and T56 uncertainties are nearly the same. Accuracies of transition temperatures are almost independent on the number of specimens and tend toward different values between -1 and $1^{\circ} \mathrm{C}$ and does not significantly affect the dependence on the number of specimens. This behaviour is probably in relation with the fair distribution of test temperature in the transition region. Skewness and excess Kurtosis coefficients tends to zero for large number of specimens indicating a trend toward normal distribution. The T41 transition temperature is almost normally distributed even for small number of specimens.

Uncertainties evolution with the number of specimens is well fitted by a power law function (Fig. 8b):

$$
u\left(T_{k}\right)=\frac{\alpha}{N^{\beta}}
$$




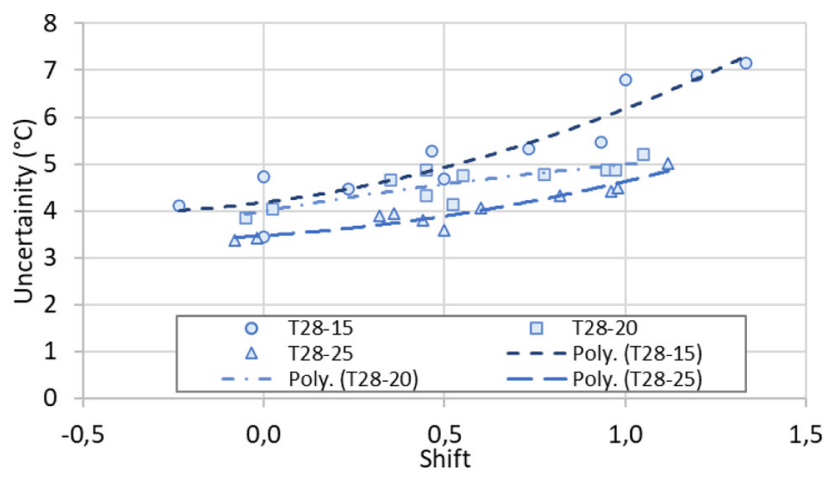

a: T28 uncertainty vs test matrix shift

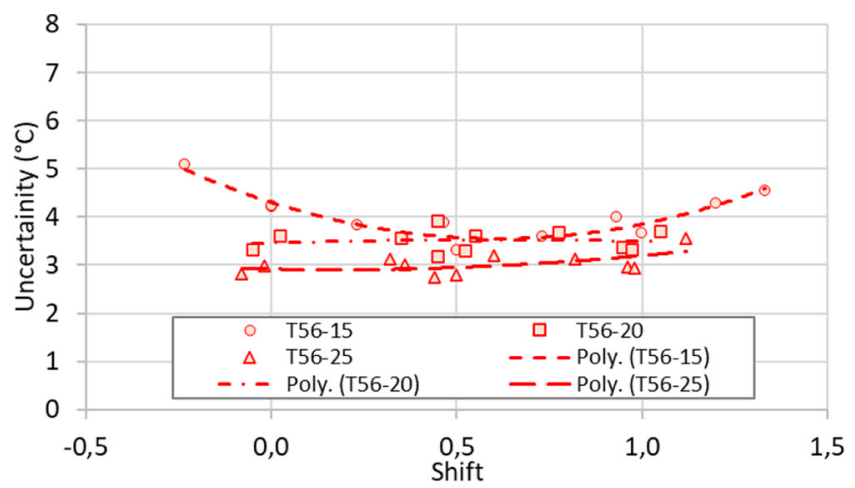

c: T56 uncertainty vs test matrix shift

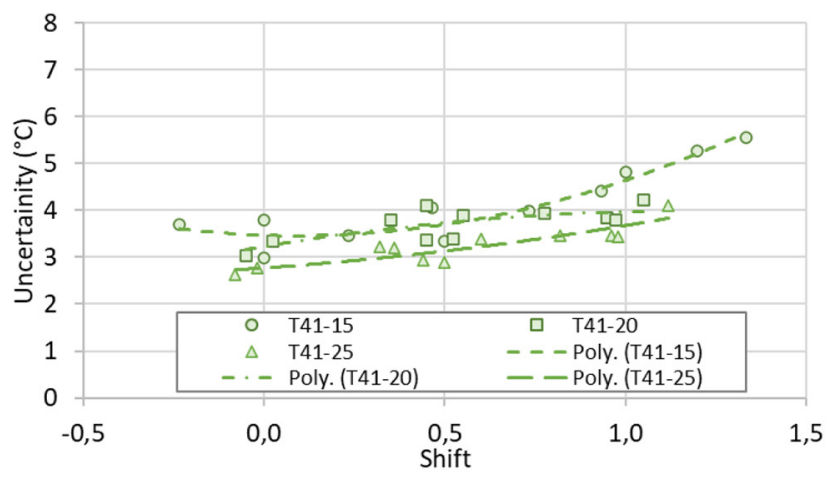

b: T41 uncertainty vs test matrix shift

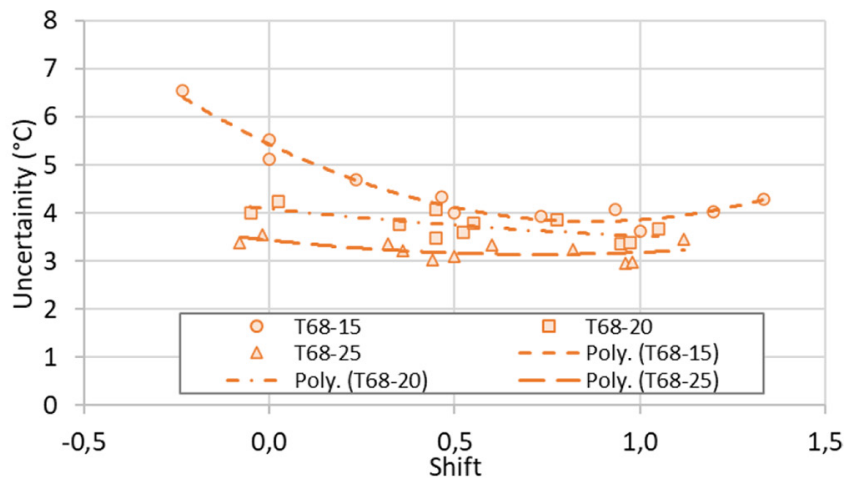

d: T68 uncertainty vs test matrix shift

Fig. 7. Evolution of the uncertainties against the test matrix shift. The dotted lines are linear or parabolic fits of the uncertainties corresponding to test matrices A with 15,20 or 25 specimens.

Table 9. Test matrices with $i$ specimens $(2 \leq i \leq 20)$.

\begin{tabular}{llllllllllllll}
\hline Test matrix B & 1100 \\
\hline Temperature $\left({ }^{\circ} \mathrm{C}\right)$ & $\mathrm{N}$ & $\mathrm{nT}$ & Shift & -100 & -80 & -60 & -40 & -20 & 0 & 20 & 40 & 60 & 100 \\
$\mathrm{Bi}$ & $5 . \mathrm{i}$ & 5 & 0.5 & & & $\mathrm{i}$ & $\mathrm{i}$ & $\mathrm{i}$ & $\mathrm{i}$ & & & $\mathrm{i}$ \\
\hline
\end{tabular}

Table 10 gives the values of the coefficients. It appears that the transition temperatures uncertainties are almost inversely proportional to the squared root of the number of specimens.

The second study of the dependence of the uncertainties on the number of specimens was conducted on matrices defined in Table 11. They are named " $C \imath$ " where " $i$ " is the number of specimens for some of the test temperatures. The number of specimens on the upper shelf is constant and equal to 3 for all the matrices. The number of test temperatures is 6 and the total number of specimens of test matrix $\mathrm{Bi}$ is 5.i.

The uncertainties of matrices $\mathrm{Ci}$ appear to be smaller than these of matrices Bi (Fig. 9). This is mostly because 5.i- 3 specimens are used, here, to define the transition region instead of $4 . \mathrm{i}$ in the case of the matrices $\mathrm{Bi}$. However, an effect of the shift,which is not constant, is also possible. As for the Bi matrices, skewness and excess
Kurtosis coefficients tends here to zero for large number of specimens indicating a trend toward normal distribution. The T28 and T41 transition temperatures are almost normally distributed even for small number of specimens.

As for matrices $\mathrm{Bi}$, uncertainties evolution with the number of specimens is well fitted by a power law function equation (5). The coefficients obtained are given in Table 12. The transition temperatures uncertainties evolution against the specimen number is slightly faster than for the matrices $B$ for the same reasons mentioned above.

\subsection{Evaluation of the uncertainty from the matrix shift and the number of specimens}

From the previous results, an expression of the uncertainties of transition temperatures as function of the matrix 


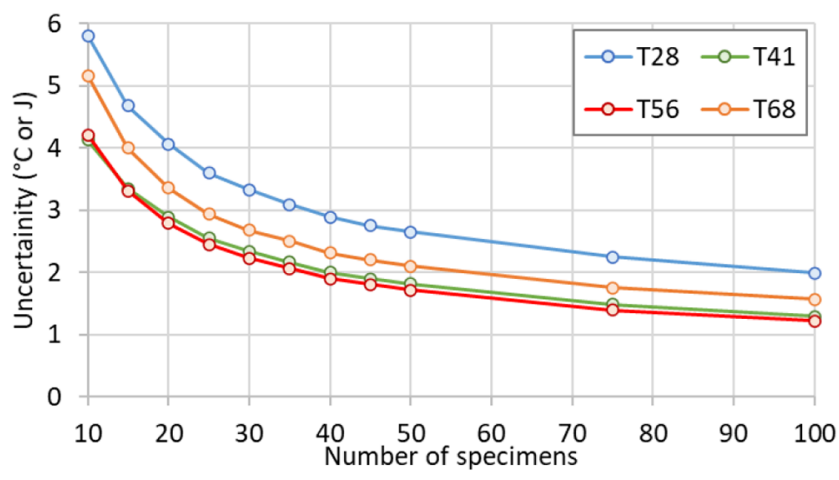

a: Uncertainties on transition temperatures

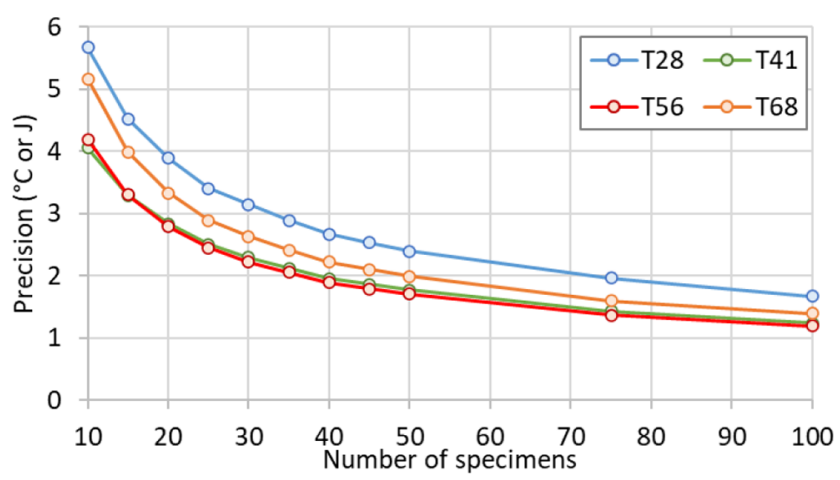

c: Precisions on transition temperatures

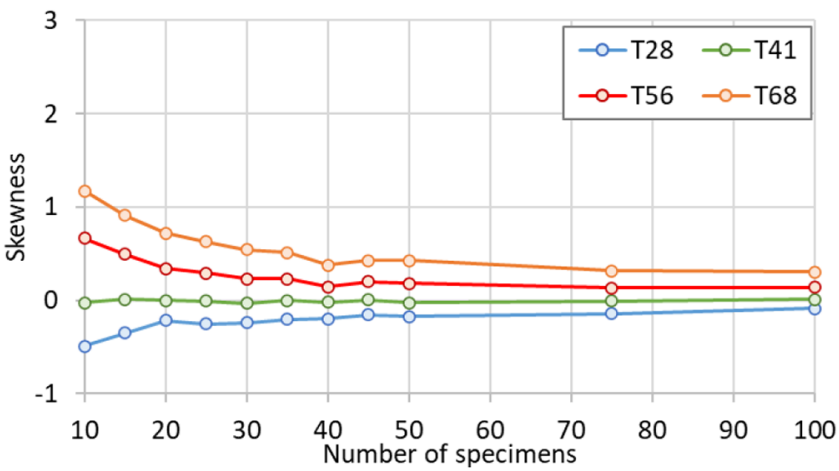

e : Skewness of transition temperatures distributions

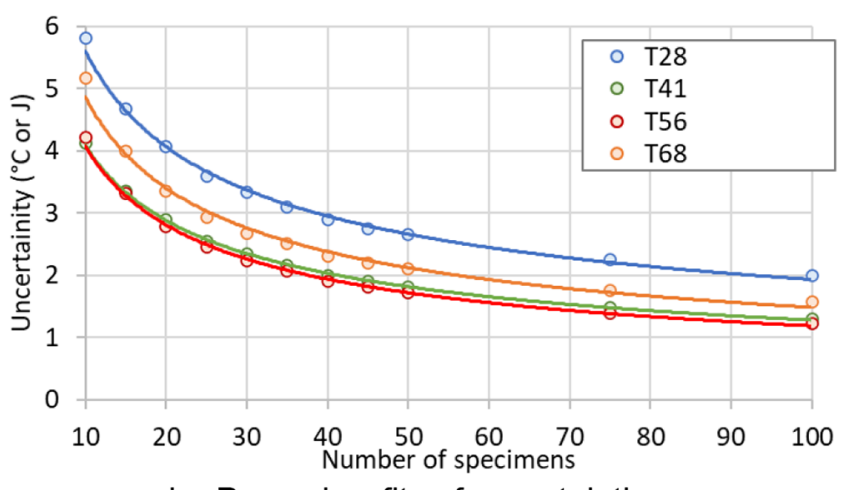

b : Power law fits of uncertainties

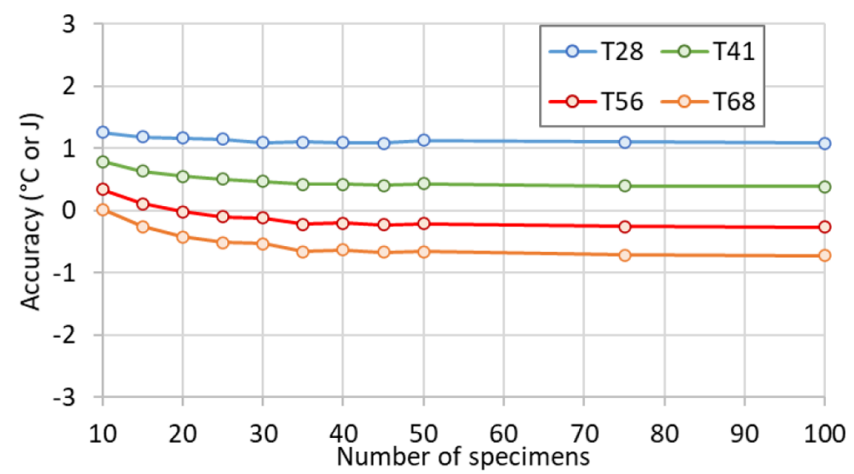

$\mathrm{d}$ : Accuracies of transition temperatures

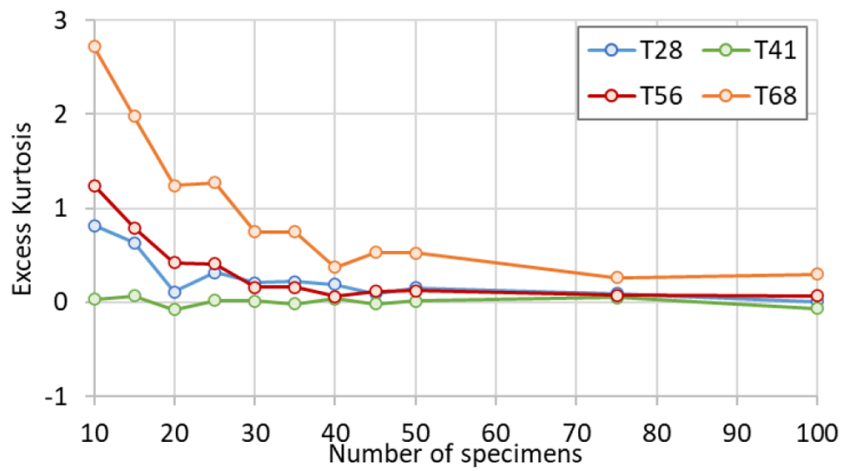

f: Excess Kurtosis of transition temperatures distributions

Fig. 8. Evolutions of uncertainties precisions, accuracies, skewness and excess Kurtosis coefficients with the number of specimens for test matrices Bi.

Table 10. Amplitude $a$ and exponent $\beta$ of equation (5) for the transition temperatures and upper shelf energy uncertainties determined from the test matrices Bi.

\begin{tabular}{lllll}
\hline Test matrix B & T28 & T41 & T56 & T68 \\
\hline Amplitude $a$ & 16.27 & 13.07 & 14.03 & 15.95 \\
Exponent $\beta$ & 0.46 & 0.51 & 0.54 & 0.52 \\
\hline
\end{tabular}

shift and of the total number of specimens of the matrix can be proposed.

In order to have a simple relationship, we assume that the uncertainties are inversely proportional to the squared root of the number of specimens, i.e. we set the exponent $\beta$ of equation (5) to 0.5. The amplitude $\alpha$ of this equation is assumed to be a parabolic function of the test matrix shift. So, the uncertainties $u$ of transition temperature $T_{k}$ is given by:

$$
u\left(T_{k}\right)=\frac{\alpha_{k}}{\sqrt{N}}=\frac{\alpha_{k} S^{2}+b_{k} \cdot S+c_{k}}{\sqrt{N}} .
$$

The coefficients $a_{k}, b_{k}$ and $c_{k}$ are tuned on the results of the simulations with the matrices A, B and C (solid lines in Figure 10). The values of these parameters are given in Table 13. An upper bound of the uncertainties on each 
Table 11. Test matrices $\mathrm{C} 2$ and $\mathrm{Ci}$ with $i$ specimens $(2 \leq i \leq 20)$.

Test matrix $\mathrm{C}$

\begin{tabular}{|c|c|c|c|c|c|c|c|c|c|c|c|c|c|}
\hline Temperature $\left({ }^{\circ} \mathrm{C}\right)$ & $\mathrm{N}$ & $\mathrm{nT}$ & Shift & -100 & -80 & -60 & -40 & -20 & 0 & 20 & 40 & 60 & 100 \\
\hline $\mathrm{C} 2$ & 13 & 6 & 0.400 & & 2 & 2 & 2 & 2 & 2 & & & & 3 \\
\hline $\mathrm{Ci}$ & $5 . \mathrm{i}$ & 6 & $7.5-\mathrm{i}$ & & i-1 & i-1 & i & i & i-1 & & & & 3 \\
\hline
\end{tabular}

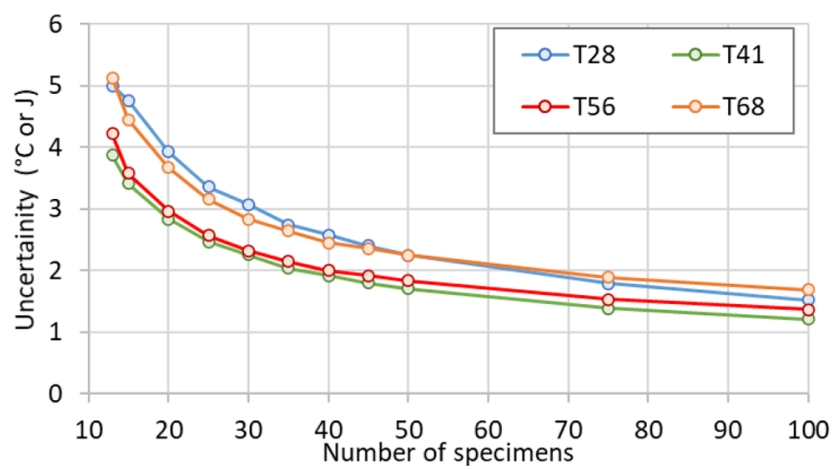

a: Uncertainties on transition temperatures

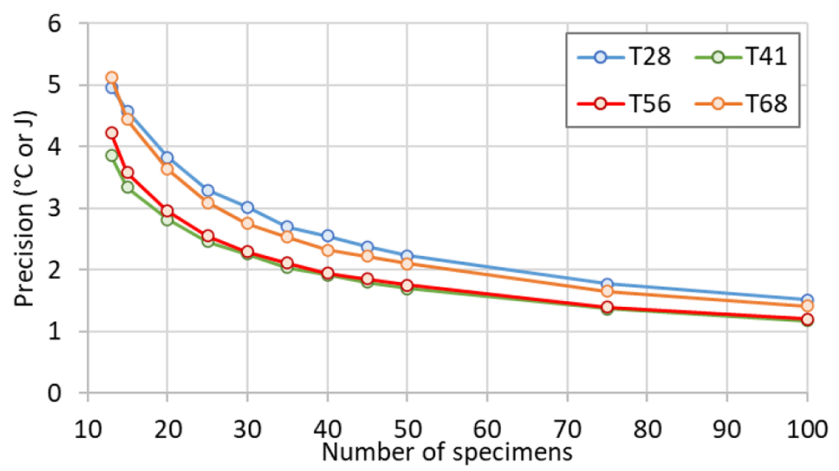

c: Precisions on transition temperatures

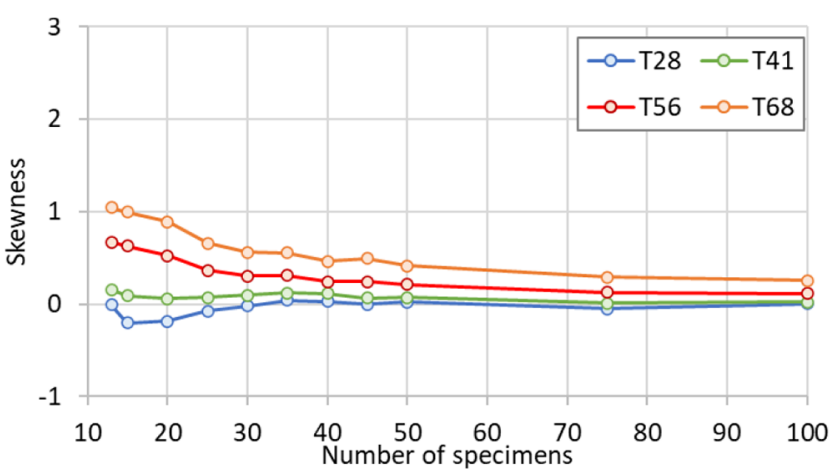

e : Skewness of transition temperatures distributions

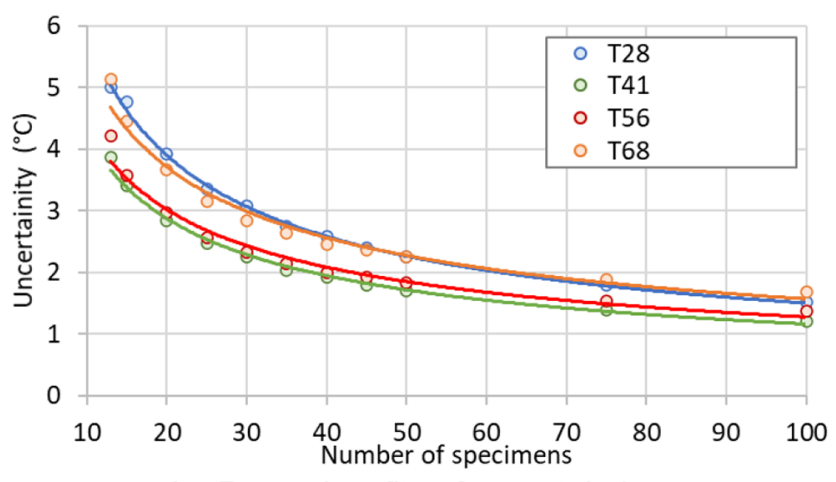

b : Power law fits of uncertainties

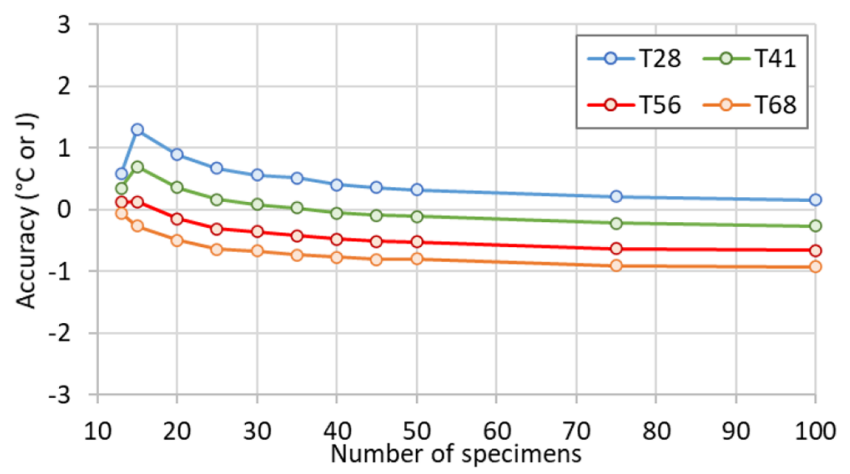

$\mathrm{d}$ : Accuracies of transition temperatures

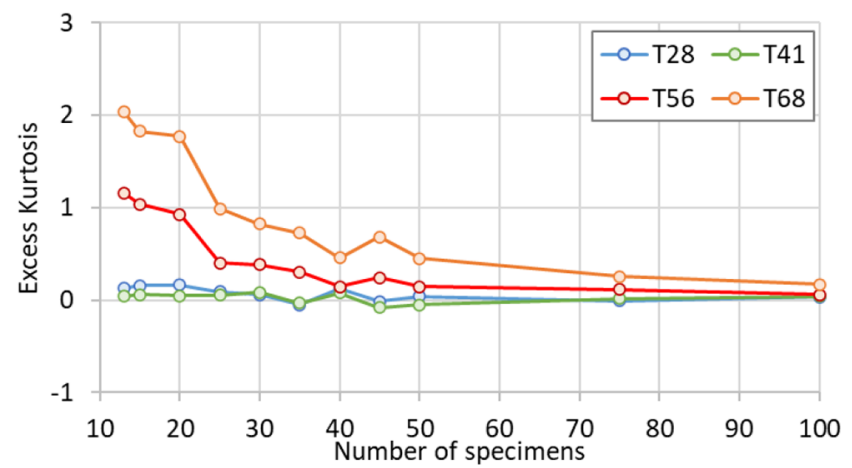

f: Excess Kurtosis of transition temperatures distributions

Fig. 9. Evolutions of uncertainties precisions, accuracies, skewness and excess Kurtosis coefficients with the number of specimens for test matrices $\mathrm{Ci}$.

transition temperature is defined by increasing the parameter $c_{k}$ in such a way that the data corresponding to the highest uncertainty amplitude $\alpha_{k}$ is on the parabolic function plot (dotted lines in Fig. 10). The values of the corresponding $c_{k}$ parameters ( $c_{k}$ upper bound) are also given in Table 13 .
Equation (6) can be checked by applying it to previous simulation results not used for the parameters tuning. We have taken the case of the first run for the "RCC-M" matrix which have a test matrix shift of 0.67 . The uncertainties given by equation (6) and of the simulation are found to be in good agreement (Tab. 14). 


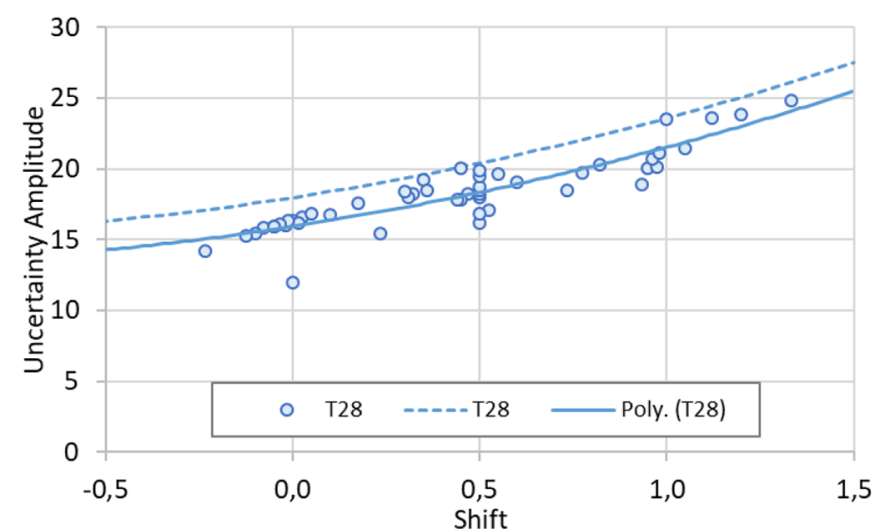

a: Uncertainty amplitude $\alpha$ for T28

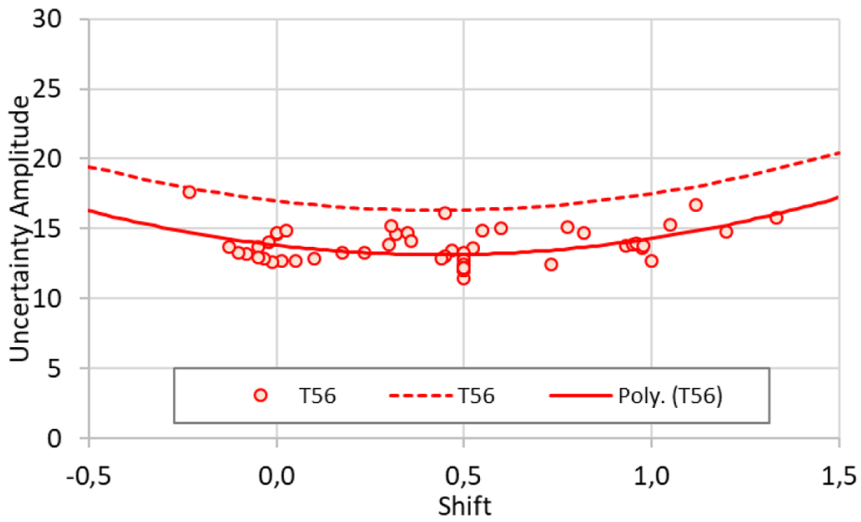

c: Uncertainty amplitude $\alpha$ for T56

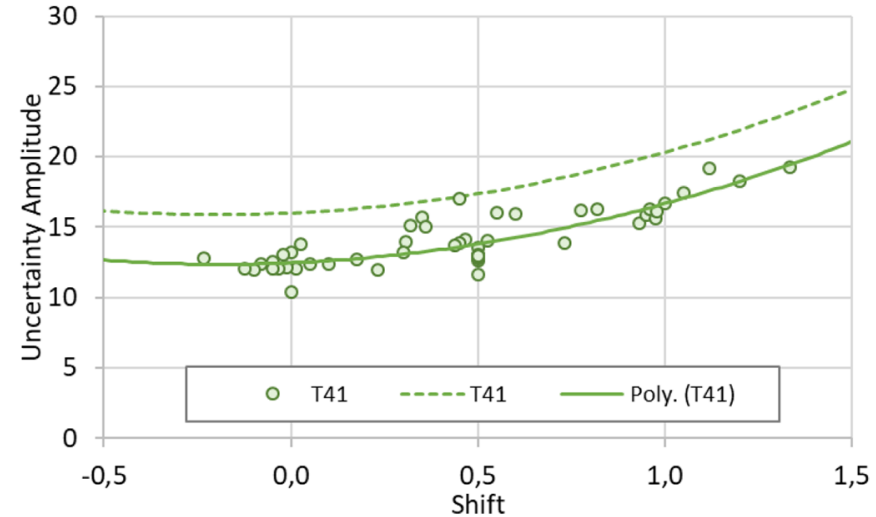

b: Uncertainty amplitude $\alpha$ for T41

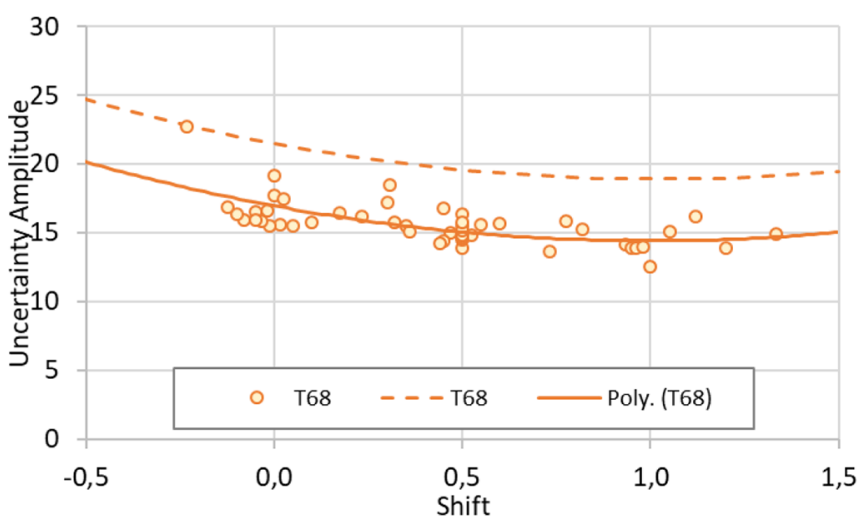

d: Uncertainty amplitude $\alpha$ for T68

Fig. 10. Uncertainty amplitude variations with the test matrix shift.

Table 12. Amplitude $a$ and exponent $\beta$ of equation (4) for the transition temperatures and upper shelf energy uncertainties determined from the test matrices $\mathrm{Ci}$.

\begin{tabular}{lllll}
\hline Test matrices Ci & T28 & T41 & T56 & T68 \\
\hline Amplitude & 23.08 & 18.45 & 15.05 & 15.05 \\
Exponent & 0.59 & 0.53 & 0.54 & 0.56 \\
\hline
\end{tabular}

Table 13. Values of the coefficients of the uncertainty amplitudes $\left({ }^{\circ} \mathrm{C}\right)$.

\begin{tabular}{lllll}
\hline & T28 & T41 & T56 & T68 \\
\hline$a_{k}$ & 1.5 & 3.1 & 3.6 & 2.5 \\
$b_{k}$ & 4.1 & 1.2 & -3.1 & -5.1 \\
$c_{k}$ best estimate & 16.0 & 12.5 & 13.8 & 17.0 \\
$c_{k}$ upper bound & 18.0 & 16.0 & 17.0 & 21.5 \\
\hline
\end{tabular}

\section{Conclusions}

Distributions of transition temperatures T28, T41, T56 and T68 have been determined using numerical simulations based on a random sampling of Charpy data. Uncertainties
Table 14. Comparison of the computed uncertainty for the "RCC-M" test matrix with the estimations of the best estimate and the upper bound of the uncertainty from equation (6). The shift of this test matrix is equal to 0.67 (Eq. (4)).

\begin{tabular}{lcccc}
\hline "RCC-M" test matrix & T28 & T41 & T56 & T68 \\
\hline$S=0.67$ & $\left({ }^{\circ} \mathrm{C}\right)$ & $\left({ }^{\circ} \mathrm{C}\right)$ & $\left({ }^{\circ} \mathrm{C}\right)$ & $\left({ }^{\circ} \mathrm{C}\right)$ \\
Simulation (Tab. 7) & 4.68 & 3.52 & 3.20 & 3.51 \\
Best estimate (Eq. (5)) & 4.57 & 3.46 & 3.14 & 3.47 \\
Upper bound (Eq. (5)) & 5.04 & 4.28 & 3.90 & 4.53 \\
\hline
\end{tabular}

on these transition temperatures have been derived, for different test matrices, from the standard deviation and the error from reference values obtained thanks to a simulation with a very large number of specimens (600).

The main conclusions of this study are:

- For large numbers of specimens $(N>30)$, distributions of $T T$ are well described by the normal distribution of same mean and standard deviation.

- For smaller numbers, distributions could be slightly asymmetric and more peaked than the normal distribution. 
- The position of the test matrix relatively to the transition temperatures range had an impact on the uncertainties. This impact is not the same for the different $T T$.

- T41 and T56 uncertainties appears to be smaller and less sensitive to the test matrix than these of T28 and T68.

- Uncertainties are approximatively inversely proportional to the squared root of the number of specimens.

- An empirical equation to estimate the uncertainties is proposed. It is a function of the number of specimen and of the shift of the test matrix.

This work was partly funded by SOTERIA, a project of the European Union's Horizon 2020 research and innovation programme. The author thanks all the contributors to the database and, in particular, the members of the fracture mechanics laboratory of the SRMA at CEA Saclay.

\section{References}

1. P. Todeschini, Y. Lefebvre, H. Churier-Bossennecn, N. Rupa, G. Chas, C. Benhamou, Proceedings of Fontevraud 7, 2-30 September 2010, Paper A084-T01
2. F.W. Stallman, Proceedings of 4th ASTM-Euratom Symposium on Reactor Dosimetry, Larch 22-26 (1982)

3. C. Brillaud, H. Augendre, M. Bethmont, Proceedings of Effect of irradiation on Materials: 17th International Symposium, ASTM STP 1270, 375-383 (1996)

4. R. Moskovic, P.E.J. Flewitt, Metallurgical and Materials Transactions A 28A, 2609-2623 (1997)

5. M.T. Todinov, Materials Science and Engineering, A265, 1-6 (1999)

6. AFCEN, RCC-M Code (2017)

7. S. Renevey, PhD Thesis, CEA-R-5784 (1998)

8. A. Rossol, PhD Thesis, EC P 98-43 (1998)

9. S. Carassou, PhD Thesis, CEA-R-5886, (2000)

10. D.J. Downing, F.M. Haggag, R.K. Nanstad, Int. J. Pres. Ves. \& Piping 44, 241-254 (1990)

11. B. Strnadel, P. Hausild, Materials Science and Engineering A 486, 208-214 (2008)

12. Y. Takashima, M. Ohata, F. Minami, Materials Science Forum Vols. 783-786, 2394-2399 (2014)

13. S. Pillot, P. Pacqueau, Engineering Fracture Mechanics 135, 259-273 (2015)

14. J.W. Eaton, D. Bateman, S. Hauberg, R. Wehbring, GNU Octave version 5.2.0 manual: a high-level interactive language for numerical computations, (2020), URL https://www.gnu.org/software/octave/doc/v5.2.0/

Cite this article as: Bernard Marini, Empirical estimation of uncertainties of Charpy impact testing transition temperatures for an RPV steel, EPJ Nuclear Sci. Technol. 6, 57 (2020) 